\title{
FINE STRUCTURE OF ROUND-HEADED HUMAN SPERMATOZOA
}

\author{
H. PEDERSEN AND H. REBBE $\dagger$ \\ Laboratory of Reproductive Biology, Department of Obstetrics and Gynecology, \\ Rigshospitalet, University of Copenhagen, and $\dagger$ Semen Analysis Laboratory, \\ Health Service Physicians Organization, Copenhagen, Denmark
}

(Received 5th April 1973)

\begin{abstract}
Summary. Two, unrelated, infertile patients presented spermiograms in which all the spermatozoa had globular heads. The most striking features of the unique ultrastructure were complete lack of both an acrosome and a postacrosomal sheath. Thin chromatin threads radiated towards the highly modified nuclear envelope. Some cells showed a partial or total absence of a nuclear envelope. Abnormally arranged mitochondria and tubular derangement in the axoneme were common findings. Such spermatozoa are incapable of fertilization.
\end{abstract}

\section{INTRODUCTION}

The improvement in electron microscopical techniques during recent years has resulted in a better understanding of the fine structure of the normal human spermatozoon (for review, see Pedersen, 1973). It has also been possible to study a few types of abnormal spermatozoa (Pedersen, Rebbe \& Hammen, 1971; Ross, Christie \& Kerr, 1971; Schirren, Holstein \& Schirren, 1971), and it is hoped that such studies might provide significant information on the basic mechanisms underlying infertility.

Occasionally, infertile males present spermiograms in which almost all the spermatozoa have round, globular heads. The sperm count and motility are 'normal'. Such cases are very suitable for electron microscopical study because of the uniform morphology. The present study records a description of the fine structure of the spermatozoa from two such cases.

\section{MATERIALS AND METHODS}

\section{Patients}

Patient A was a 28-year-old butcher and Patient B was a 26-year-old sales manager. Their childless marriages were of 8 and 3 years' duration respectively. Three years before the present study, Patient B had a non-specific penile ulcer with inguinal lymphadenitis, which was cured by antibiotic treatment. Otherwise, both patients had been healthy, and had normal masculine development with scrotal testes of normal size and consistency. Hormone assays of pituitary, thyroid and adrenocortical function were normal, as were routine blood and urine analyses. Wassermann and gono-reactions were negative. In Patient B, 
testicular biopsy and chromosome analysis did not show specific changes. As shown in Table 1, high percentages of rounded sperm heads were present in the ejaculates of both patients.

Table 1. Analyses of semen samples from two infertile males

\begin{tabular}{|c|c|c|c|c|c|}
\hline & \multicolumn{2}{|c|}{ Patient A } & \multicolumn{3}{|c|}{ Patient B } \\
\hline & Fuly 1971 & Oct. 1971 & Fune 1970 & Jan. 1971 & March 1971 \\
\hline Abstinence (days) & $3 \frac{1}{2}$ & $2 \frac{1}{2}$ & 3 & $3 \frac{1}{2}$ & $3 \frac{1}{2}$ \\
\hline Hours after ejaculation & 1 & $3 / 4$ & $1 \frac{1}{2}$ & 2 & $1 \frac{1}{2}$ \\
\hline Semen volume $(\mathrm{ml})$ & 4 & $5 \cdot 5$ & 4.5 & $4 \cdot 0$ & $2 \cdot 5$ \\
\hline Immotile sperm. $(\%)$ & 66 & 61 & 53 & 45 & 53 \\
\hline Grade of motility & $\begin{array}{l}\text { Fairly } \\
\text { good }\end{array}$ & $\begin{array}{l}\text { Fairly } \\
\text { good }\end{array}$ & Good & Good & $\begin{array}{l}\text { Fairly } \\
\text { good }\end{array}$ \\
\hline Concentration $\left(\times 10^{6}\right)$ & 81 & 67 & 61 & 83 & 125 \\
\hline Round heads $(\%)$ & 97 & 100 & 98 & 100 & 100 \\
\hline
\end{tabular}

\section{Electron microscopy}

Ejaculates from the two patients were processed for electron microscopy by the method which has been previously described in detail (Pedersen, 1972a). The tissue was fixed in collidine-buffered glutaraldehyde and post-fixed in osmium tetroxide in the same buffer. After dehydration in ethanol and propylene oxide, the tissue was embedded in Epon 812 (Luft, 1961). Sections were stained with methanolic uranyl acetate and lead citrate and examined in a Siemens Elmiskope 101 electron microscope.

\section{RESULTS}

The principal abnormalities which affected the spermatozoa of both patients were the complete lack of both the acrosome and the postacrosomal sheath. No spermatozoa with normal acrosomes were observed. The nucleus was often eccentrically placed with respect to the sperm tail, and was further characterized by its ball-shaped chromatin (Pl. 1, Fig. 1 and Pl. 2, Fig. 2). Contrary to what was found in 'normal' spermatozoa, the nuclear envelope was separated from the chromatin by a wide light space. Some of this space was occupied by fine threads radiating from the centrally placed chromatin (Pl. 1, Fig. 1).

The inner and outer parts of the nuclear envelope were frequently widely separated, with the formation of a large light compartment, which was often more voluminous than the nucleus itself (Pl. 1, Fig. 1 and Pl. 3, Fig. 4). Occasionally, the nuclear envelope was almost completely absent (Pl. 2, Fig. 2 and Pl. 3, Fig. 3) and there was free communication between the nuclear material and the cytoplasm. The inner part of the nuclear envelope frequently formed paired membranes which were interconnected by regularly spaced densities (Pl. 3, Fig. 3). In areas of more 'normal' appearance, the nuclear envelope contained nuclear pores (Pl. 1, Fig. 1 and Pl. 3, Fig. 3), thus imitating the redundant nuclear envelope of 'normal' spermatozoa (Pedersen, 1972b). 


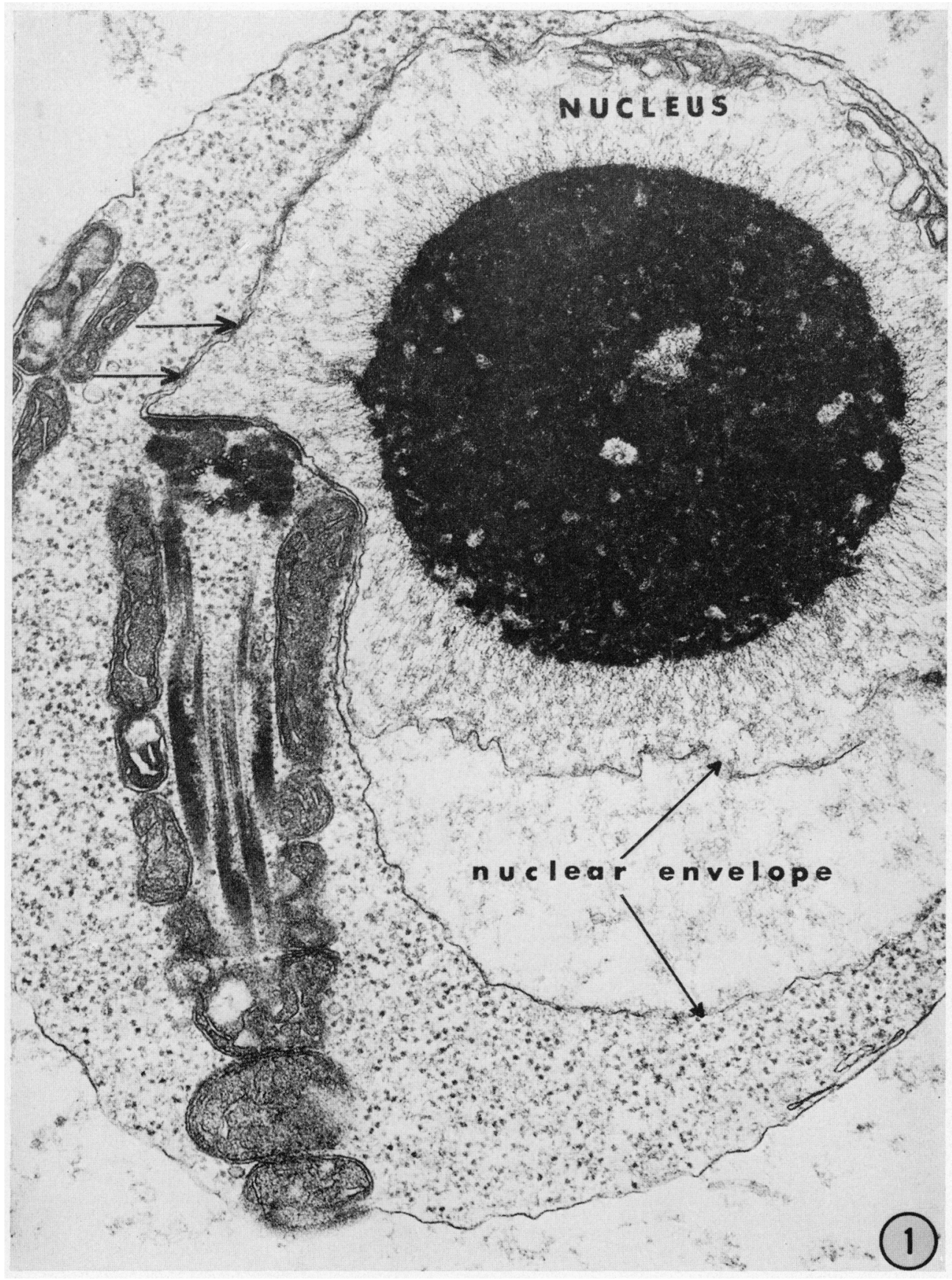

All the electron micrographs are of spermatozoa from one or other of two infertile male patients. Fig. 1. A nucleus containing a globular aggregation of chromatin of normal appearance from which fine threads radiate towards the nuclear envelope. The two membranes of the nuclear envelope are widely separated. Nuclear pores are visible in localized areas (arrows). $\times 41,000$.

(Facing p. 52) 


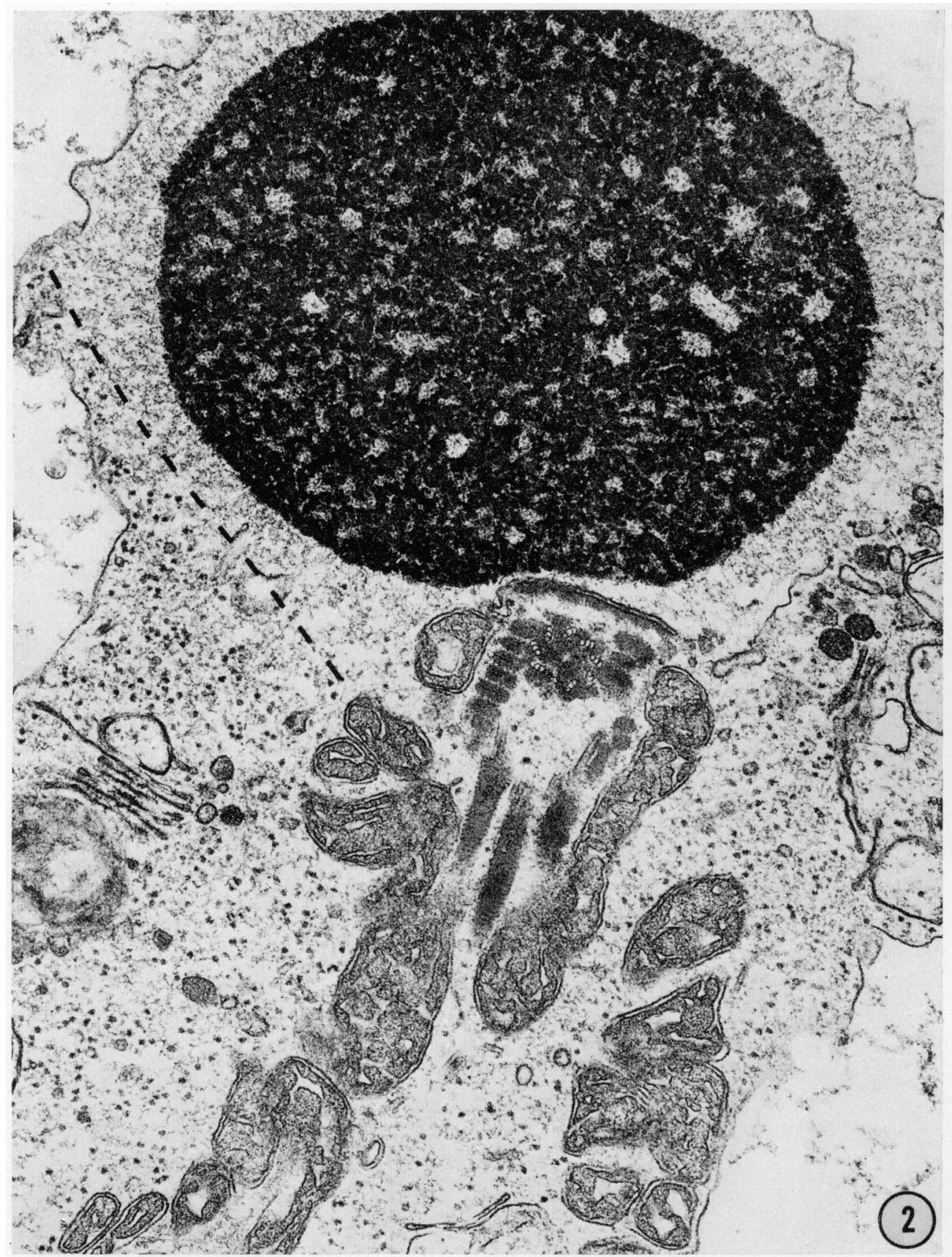

Fic. 2. The nuclear cnvclope is totally lacking, and there is a free intermingling of nuclear and cytoplasmic substances (dotted linc). Neither an acrosome nor a postacrosomal sheath can be recognized. The arrangement of the mitochondria is abnormal, $\times 56,000$. 

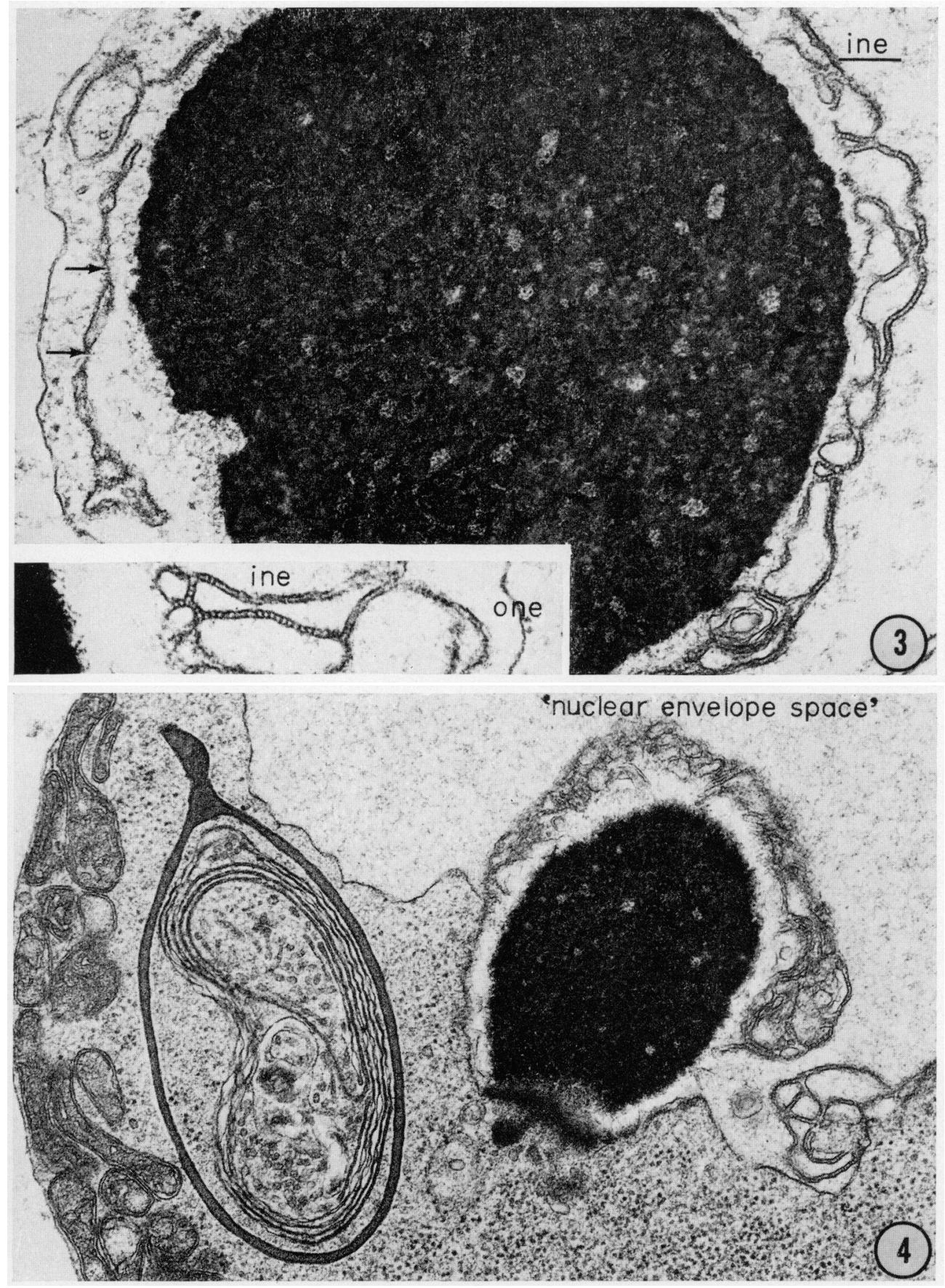

Fici. 3. The nuclear envelope shows a different appearance in different parts of the same cell. Apparently normal nuclear pores (arrows) are present in certain areas while in other areas the nuclear envelope is lacking. The inner part of the nuclear envelope (ine) and its outer part (onc) may be widely separated. The inset shows that the inner part may form paired membranes interconnected by regularly spaced densities. $\times 53,000$ (inset $\times 65,000)$.

Fig. 4. The two membranes of the nuclear envelope are widely separated forming a 'nuclear envelope space' more voluminous than the nucleus itself. An abnormally situated Golgi complex is surrounded by an acrosome-like structure. The mitochondria are found in a highly abnormal position. For details sce lig. $5 . \times 32,000$. 


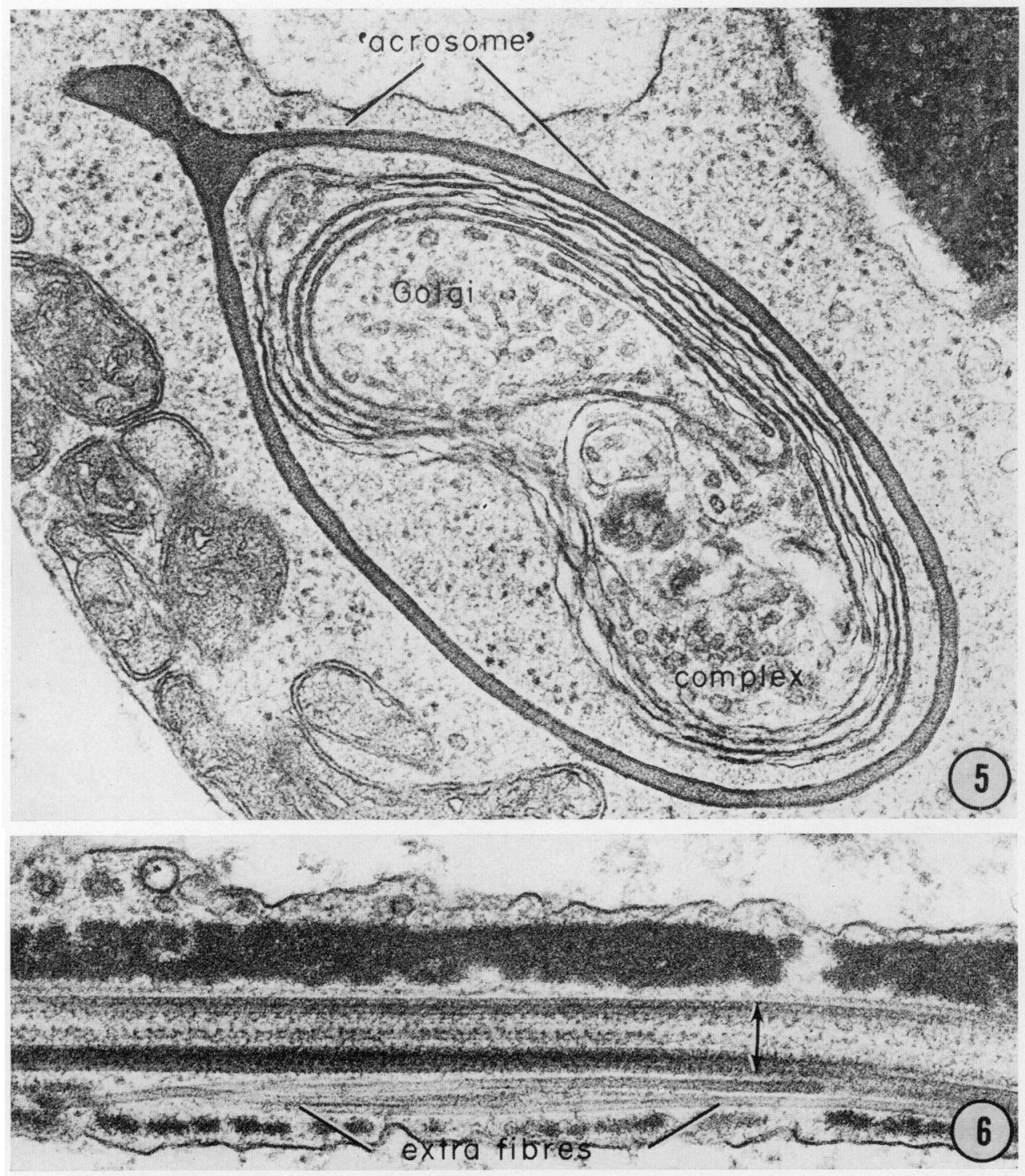

Fig. 5. Magnified detail of Pl. 3, Fig. 4 showing the Golgi complex surrounded by an abnormal acrosome. $\times 55,000$.

FIG. 6. The double-headed arrow indicates the axoneme. Between this and the fibrous sheath, some extra fibres are observed. Such extra fibres and tubular derangement are frequently observed in round-headed spermatozoa. $\times 56,000$. 
Apart from the shape of the chromatin, and the presence of threads radiating from it, the chromatin itself had a 'normal' appearance.

On very rare occasions, remnants of an acrosome could be recognized, sometimes in relation to a Golgi complex (Pl. 3, Fig. 4 and Pl. 4, Fig. 5), but always abnormally situated.

Tail abnormalities were frequent. The mitochondria were usually arranged in a more disorderly manner than in normal cells (Pl. 1, Fig. 1, Pl. 2, Fig. 2, and Pl. 3, Fig. 4). Axonemes with abnormally arranged tubular elements or tubular derangement and tail coilings were frequently observed (Pl. 4, Fig. 6).

The cytoplasm was nearly always more granular than that seen in normal spermatozoa.

In general, the spermatozoa were well preserved for electron microscopy indicating that they were living and not degenerating when ejaculated. No significant difference was observed between the spermatozoa of the two patients.

\section{DISCUSSION}

In mammalian fertilization, a normal acrosome reaction is necessary for sperm penetration of the egg investments, so the absence of an acrosome is clearly incompatible with the participation of spermatozoa in fertilization. The rôle played by the postacrosomal sheath is at present unknown, but this region is apparently involved in the initial stages of sperm-egg fusion (for review, see Bedford, 1972).

The significance of the nuclear abnormalities, the shape of the chromatin, the radiating chromatin threads and the various changes in the nuclear envelope is unknown. The dissolution of the chromatin around the periphery, and the partial absence of the nuclear envelope in localized areas are reminiscent of the events of pronucleus formation, but supporting evidence for such a premature 'activation' of the sperm nucleus is lacking. Paired membranes with interconnecting ribs formed by the inner nuclear envelope are also occasionally observed in the redundant nuclear envelope of spermatozoa in 'normal' ejaculates (Pedersen, 1972b).

The present study does not contribute to solving the problems involved in the shaping of the sperm head during spermiogenesis. From comparative observations on sperm structure and spermiogenesis, Fawcett, Anderson \& Phillips (1971) conclude that the shape of the sperm head is largely determined by genetically controlled protein and DNA aggregation during chromatin condensation, and not, as previously suggested, by externally applied modelling of the chromatin by the acrosome or the microtubules of the manchette. The morphological observations of the present work do not allow a conclusion on this point, but stress the importance of studying spermiogenesis in such patients. One patient had been subjected to testicular biopsy before the present study, and could not be persuaded to agree to a further biopsy. The other patient was unwilling to undergo a testicular biopsy.

The fact that these two unrelated patients presented identical spermiograms and that a similar picture has been described by Schirren et al. (1971) suggests 
that this sperm abnormality represents a well-defined entity, and not just an accidental sperm defect. Further studies on such cases, including electron microscopy, DNA determinations and cytochemistry, might provide information of value to an understanding of normal sperm morphogenesis.

\section{ACKNOWLEDGMENTS}

We are greatly indebted to Professor Nils Björkman for generously letting us use his electron microscope, and to Professor Harald Moe for placing his photographic equipment at our disposal.

\section{REFERENGES}

BEDFoRd, J. M. (1972) Sperm transport, capacitation and fertilization. In Reproductive Biology. Eds. H. Balin and S. Glasser. Excerpta Med. Fdn, Amsterdam.

Fawcett, D. W., Anderson, W. A. \& Phillips, D. M. (1971) Morphogenetic factors influencing the shape of the sperm head. Devl Biol. 26, 220

LUFT, J. H. (1961) Improvements in epoxy resin embedding methods. F. biophys. biochem. Cytol. 9, 409.

Pedersen, H. (1972a) The postacrosomal region of the spermatozoa of man and Macaca arctoides. 7. Ultrastruct. Res. 40, 366.

Pedersen, H. (1972b) Further observations on the fine structure of the human spermatozoon. $Z$. Zellforsch. mikrosk. Anat. 123, 305.

Pedersen, H. (1973) The human spermatozoon. An electron microscopical study including comparative details of Macaca arctoides spermatozoa. Dan. med. Bull. (In press).

Pedersen, H., Rebbe, H. \& Hammen, R. (1971) Human sperm fine structure in a case of severe asthenospermia-necrospermia. Fert. Steril. 22, 156.

Ross, A., Christie, S. \& KerR, M. G. (1971) An electron microscope study of a tail abnormality in spermatozoa from a subfertile man. $\mathcal{J}$. Reprod. Fert. 24, 99.

Schirren, G. G., Holstein, A. F. \& Schirren, G. (1971) Uber die Morphogenese rundköpfiger Spermatozoen des Menschen. Andrologie, 3, 117. 